\title{
Operative treatment as a part of the comprehensive care for patients with injuries of the thoracolumbar spine. A review*
}

\author{
A Alho MD PhD \\ Orthopaedic Department, Ullevaal Hospital, University of Oslo, N-0407 Oslo, Norway.
}

In a total appraisal, the advantages and drawbacks of operative decompression and stabilisation of the injured thoracolumbar spine should be evaluated in the treatment of a paraplegic patient and of a patient without neural damage. Operative treatment may be advantageous independent of its effect on the neural damage. Only a few studies allow direct comparison between operative and conservative treatment. Some studies are only of historical value. Today, a general operative policy is to use Harrington rods in the thoracic spine. For injuries caudal to the 9th thoracic vertebra and for those with injuries in the lumbar spine, internal fixators with transpedicular screws are used. Anterior decompression and stabilisation are also warranted in some cases. New implants are continuously being developed, e.g. implants which combine the advantages of hooks and pedicular screws. No study shows conclusively that operative treatment improves the neurological status compared with conservative care. Conservative and operative treatment may both have particular complications. It appears that neurological deterioration is more likely to occur after conservative treatment, while complications related to wound healing and from the implants burden the operative alternative. Mobilisation is quicker and easier after operative treatment, improving psychological and social rehabilitation. Also, these patients experience less in the way of chronic back pain. A high level of expertise is required for operative treatment and this illustrates the general need for the centralisation of the treatment of these relatively rare and severe injuries.

Keywords: spinal cord injury; thoracolumbar spinal fractures; operative treatment; surgical treatment; conservative treatment; outcome.

\section{Introduction}

Patients with traumatic paraplegia return to independent life at an increasingly good functional level as a result of improved medical and surgical care and effective rehabilitation. In a total appraisal of operative care it is important to evaluate the advantages and drawbacks of operation both in the treatment of a spinal cord injured (SCI) paraplegic patient and of a SCI patient without neural damage. It seems useful to evaluate operative reduction and internal fixation of such fracturedislocations independent of the effect on the neural damage.

*This paper was read at the Third Scientific Meeting of the Scandinavian Medical Society of Paraplegia, Lahti, Finland, 9-11 September 1993.
Operative reduction and internal fixation have been developed to allow early and secure mobilisation and, thus, to improve the total outcome. It is not supposed that an optimal reduction and stabilisation of the spine would be effective in the recovery of the damaged central nervous tissue. The goal is to create optimal conditions for the conservation of the undamaged neural tissue that may be left after the injury.

When comparing concurrent conservative and operative care certain criteria should be made for the operative methods. Laminectomy as the only procedure is either ineffective or detrimental ${ }^{1,2}$ and is therefore outdated. Only patients where laminectomy has been combined with an adequate fixation procedure should be considered for present-day comparisons. Fixation with 
Meurig-Williams plates or with similar items does not fulfil the criteria for adequate reduction and stabilisation. Using the modern cirteria of adequate operative procedures, some comparisons between conservative and operative treatment ${ }^{3,4}$ are only of historical value.

The modern era of operative reduction and internal fixation started with Harrington rod instrumentation. ${ }^{5}$ Nowadays, only fixation methods as strong or stronger than Harrington rodding should be considered when comparing operative and non-operative treatment.

Operative treatment is by no means an alternative to active conservative care, and does not replace any of the components of good conservative care. ${ }^{6}$ It is only an adjunct, although an important one; everything else concerning patient care remains the same.

The questions that should be addressed concerning the evaluation of operative care are as follows.

1 Is the consolidation of the spine improved by operative fixation, and what functional gain may this give?

2 Does operative decompression improve the neurological result?

3 Does the quicker rehabilitation after internal fixation affect the total result of care?

4 Do the potential advantages of operative treatment outweigh the complications which affect the outcome in some patients?

The outcome of care is a complex equation, and an analytical approach is necessary. This review is an effort to address the different factors of the total outcome equation.

\section{Discussion}

\section{Stability of the thoracolumbar spine}

When considering the role of operative treatment, understanding posttraumatic instability of the spine is important. The definitions of stability/instability have changed since the pioneer work of Holdsworth, ${ }^{7}$ but his basic principle - the funda- mental stabilising effect of intact posterior elements - is unaltered. ${ }^{8,9}$

Denis $^{10}$ created the concept of three columns, which McAfee et al ${ }^{11}$ developed further. The common flexion compression fracture affects the anterior column only; the fracture is stable as long as the two other columns - the middle and posterior column-are intact. An axial burst fracture affects the anterior and middle column encroaching onto the spinal canal to varying degrees. The instability of the posterior column is a component of a major global instability and is usually associated with spinal cord injury.

Another way of looking at the injury is to quantify the degree of instability. ${ }^{9,10}$ Instability of the first degree is a mechanical one with a risk of kyphosis. An extensive flexion compression fracture requires an 'orthopaedic' correction only to prevent later deformity and pain. Instability of the second degree is neurological and includes risk for neurological deterioration; a burst fracture with posterior displacement of vertebral body fragments is the typical example. Instability of the third degree is both mechanical and neurological as in an unstable fracture-dislocation, where both stabilisation and decompression are important.

\section{Performance of the internal fixation implants}

In planning the care of a paraplegic patient, it is important to look at the skeletal injury separately from the neural one. If distraction fixation is beneficial for a patient without spinal cord injury, it may be useful for a paraplegic patient as well. The risk of the operation itself is not increased because of a concurrent spinal cord injury. ${ }^{12,13}$

The history of the operative treatment of the fractured, unstable spine has not been a story of continuous success. Faulty methods have been used and useful methods have been wrongly used. The first trials of internal fixation were done by the easiest surgical approach, the posterior one. Plates were placed on both sides of the spinous processes and fixed with nuts and bolts. Some stability was achieved, but the result 
was often far from what is achieved by the modern criteria for stable internal fixation. Problems were experienced concerning both stability and wound healing, especially in paraplegic patients. ${ }^{14}$

As mentioned above, the breakthrough for modern internal fixation took place with the introduction of Harrington rods, originally designed for the treatment of scoliosis, for the stabilisation of the injured thoracolumbar spine. ${ }^{5.15}$ Until to-day, Harrington rod fixation has been considered to be the 'gold standard'. ${ }^{16}$ However, several problems have been experienced: the hooks may loosen from the laminae, the rods may break and the patients' backs are stiff during and after fixation because of the large operative approach. ${ }^{17}$

Rimoldi et al ${ }^{18}$ examined 147 patients with unstable low thoracic and lumbar spine fractures; 56 had complete and 91 incomplete neurological lesions. They found that the use of sublaminar wires improved the fixation as compared with the use of Harrington rods alone. Laminectomy as a part of the procedure was not beneficial.

In the studies of Wörsdörfer ${ }^{19}$ and Dick ${ }^{20}$ the strength and stability of several implants were compared, with intact and unstable spine specimens as controls. The stiffness of the Harrington rod fixation and Dick's fixateur interne were close to that of intact spine. However, the ultimate bending strength of the spine/implant construction in Harrington fixation was only $6-10 \mathrm{Nm}$, which is incompatible with maximal daily loads, while fixateur interne tolerated a load of $47 \mathrm{Nm}$, much above the in vivo loads.

In reported clinical studies, internal fixation with transpedicular screws and connecting rods has been performed satisfactorily. ${ }^{12,13}$ Lindsey \& Dick ${ }^{13}$ treated 80 consecutive patients, 27 with complete and 53 with incomplete neurological deficits, using transpedicular distraction fixation and intracorporeal bone transplantation. A significant number of patients, 14 out of 28 Frankel B and C, were noted to improve by one full level. None of the patients experienced deterioration in their neurological status. Seventy per cent of their patients wore a light 3-point orthosis postoperatively, while $30 \%$ had no external support.

\section{Decompression effect}

Most thoracolumbar spinal injuries occur at the thoracolumbar junction where the neural injury is a combination of nerve root damage and spinal cord injury. The former is a peripheral nerve injury which may have a healing capacity. Therefore, restoration of the anatomy and decompression of the neural elements may be beneficial.

Operative treatment by distraction fixation combines the principles of stabilisation and decompression. By distraction of the spine, realignment of the fragments may be achieved because of the remaining ligamentous continuity (ligamentotaxis effect). ${ }^{5,16,21}$ Such an indirect decompression is not always fully effective. Therefore, approaches for direct decompression by removal of the encroaching, protruding fragments have been carried out. ${ }^{22}$

Laminectomy, which was previously considered as a method to obtain decompression, has been found to be ineffective ${ }^{1}$ except for the few cases where a laminar fracture is displaced anteriorly. Laminectomy fails to relieve an anterior compression and increases spinal instability. ${ }^{23,24}$ Already in the early 1930s it was realised that decompression of tuberculous spondylitis should be done anteriorly, where the pathology is usually located. ${ }^{25}$ Amazingly, this thinking was not extended to the treatment of thoracolumbar or cervical injuries before the late 1950s-early 1960 s.

\section{What type of surgery and how much surgery?}

Distraction fixation does not reduce all the bony fragments displaced in the spinal canal. Therefore, some surgeons have felt that laminectomy or some other approach to reduce those fragments requires to be used together with the stabilisation procedure. As mentioned above, such an extension of the surgical procedure increases the risk of operative complications without any real benefit.

The severity of the initial trauma is quite decisive for the prospects of recovery, and the type of bone injury has major prognostic importance. $^{26}$ Posterior instrumentation realigns the spine and usually restores the 
canal patency to greater than $50 \%$. The effect is greatest if the operative reduction is carried out within the first 4 days following injury. ${ }^{27}$

However, there is no close correlation between neurological improvement in those with incomplete SCI and the amount of increase of spinal canal area. ${ }^{28}$ Therefore, exact reduction of fragments may not be necessary. Fidler ${ }^{29}$ made an interesting observation using $\mathrm{CT}$ scans after conservative treatment of burst fractures, and observed that the narrowing of the spinal canal was progressively relieved by natural remodelling of the fragments retropulsed in the spinal canal. A similar observation was made by others. ${ }^{30}$

Based on these observations, it may be concluded that a useful concurrent operative policy is to utilise Harrington rods in the thoracic spine where stability is easier to obtain than in the lumbar spine. Also, the pedicles above the 9th thoracic vertebra are too narrow to allow screw fixation. In lower thoracic spinal injuries below the 9th thoracic vertebra and in the lumbar spine, stronger internal fixators with transpedicular screws may be used. In some cases, anterior decompression and even fixation may be warranted. New implants are continuously being developed, e.g. implants which combine hooks and pedicular screws.

\section{Consolidation of the spine}

The goal of operative reduction and internal fixation is not only to reduce or remove displaced fragments, but also to obtain stable healing of the skeletal injury.

Most injuries of the spine unite, late instability being an exception. ${ }^{31}$ Currently the question regarding the general care of injuries is not whether conservative means can be used to achieve healing. The same applies for those with SCI. The question is in what time, at what cost and with what functional outcome the consolidation of the injury is obtained. ${ }^{32}$ According to Whitesides, ${ }^{9}$ unstable fractures cannot be expected to become stable spontaneously; the deformity and the neural injury may pro- gress and potential neurological recovery may be inhibited.

Neurological deterioration in patients with SCI Frankel grade E was reported by Denis et al $^{33}$ after conservative treatment of 39 patients with burst fractures. Two patients developed paraparesis (grade C) and were unable to work; another two patients developed motor and sensory changes due to radicular compression (grade D); two further patients developed sciatica.

In the series of McEvoy \& Bradford ${ }^{34}$ six out of 22 conservatively treated patients were operated on later, three because of neurological deterioration and three because of kyphosis or pain.

\section{How to compare conserative and operative treatments?}

Comparison of operative and conservative treatment can only be made in comparative series. In a series of conservatively treated burst fractures at the T10 to L5 levels by Weinstein et al, ${ }^{35} 78 \%$ of the patients belonged initially to Frankel grade E, and one patient was grade $\mathrm{A}$. In another series of operatively treated burst fractures of the segments T4-L5 by Kostuik et al ${ }^{22}$ only $29 \%$ of the patients had intact neurology initially, and $5 \%$ were grade A.

The types of injuries having the greatest chance of recovery ${ }^{26}$ are not usually described in sufficient detail to make comparisons between series possible. The Frankel ${ }^{31}$ scale which is useful in epidemiological comparisons is not sensitive enough to describe details of neural recovery. Scales such as the Motor Trauma Index Score of the American Spinal Injury Association ${ }^{26.28}$ should be used more widely.

There have been doubts regarding the benefits of surgery. In 1979 Bedbrook $^{3}$ stated 'so far, I am not convinced, after retrospective study, of the value of (such) operations'. However, neither the previous reports in his review nor his own series included cases where any of the modern distraction fixation methods would have been used. Today, the comparison of operative and conservative treatment has to 
be done by comparing the present alternatives, not the historical ones.

Few reports give sufficient individual data to make matching of cases between two series possible in a metaanalysis. For these reasons, the task of reviewing the few reports where comparison really can be made, is a very manageable one.

\section{Comparative series}

Six recent reports seem to fulfil the basic criteria for the comparison of conservative and operative treatments in terms of fracture location, neurological grade, neurological improvement and reporting of complications (Table I).

An important aspect is whether operative treatment introduces risks for complications which are not seen with conservative care. Firstly, neurological impairment which theoretically might be involved in the operative manipulation of the injured spine and cord has not been reported when Harrington fixation has been used. ${ }^{33.36-39}$ The same is true of the transpedicular screw/rod fixation; no neurological impairments have been reported in controlled series. ${ }^{12,13.40}$

Whether operative reduction and internal fixation alter the natural history in patients with spinal cord injury is still an unanswered question. Jacobs et al, ${ }^{36}$ Soreff et al, ${ }^{37}$ and Willén et $a l^{38}$ did not show any significant difference in results between patients treated conservatively and patients treated with Harrington rods.

Comparing the rates of deep venous thrombosis and pulmonary embolism, it seems that these complications may be more common after operative treatment. ${ }^{36,39}$ However, the differences are not significant.

Neurological deterioration because of remaining instability has been reported in two conservatively treated series. ${ }^{33,34}$

Any implant used to fix an unstable skeletal structure may fail. Failures were, indeed, common after the first Harrington rod fixations; ${ }^{15,17}$ in particular the reduction result was lost and the kyphotic deformity recurred. Changes in the rod and hook design and the use of sublaminar wires have improved rod fixation. Transpedicular screws may break ${ }^{40}$ but none of the local complications, including infection, have had disastrous consequences in the reported series. Obviously, improvement has to be made in the implant design.

Including neurological impairments (Table I) and summing up all complications, there were 56 complications among 169 conservatively treated patients $(33.1 \%)$ and 71 complications among 187 operatively treated patients $(38.0 \%)$.

\section{Effects of operative treatment on rehabilitation and outcome}

The advantage of any modern operative fracture fixation is improved mobilisation of the patient. In the series of Jacobs et $a^{36}$ paraplegic patients were candidates for ambulation 7 weeks after conservative care and 2.5 weeks after operative treatment; they could sit in a wheelchair at 10 and 5 weeks, respectively. In the series of Willén et al ${ }^{38}$ the time of recumbency was $67 \pm 11$ $(\mathrm{M} \pm \mathrm{SD})$ days in the conservatively treated and $18 \pm 8$ days in the operatively treated patients; paraplegic patients stayed in the hospital for $207 \pm 95$ days with conservative care, and $157 \pm 127$ days after Harrington fixation.

A patient with a total loss of cord function may have a poor prognosis concerning neurological recovery. However, operative fixation may have other important benefits in such cases. The operation is performed to permit early mobilisation and to prevent the morbidity of long recumbency. The reduced expense of management is not unimportant, either. ${ }^{41}$ By treating fracture dislocations of the thoracolumbar spine with Harrington instrumentation, hospital stay and costs have been reduced by $50 \% .{ }^{21}$

Osti et $a l^{39}$ reported that only five of 30 conservatively treated patients were painless at 6 years, compared with 15 of 39 operated patients. Denis et $a l^{33}$ reported that all patients in a series without neural damage operated with Harrington rods were able to return to work with minimal pain, whereas only $75 \%$ of the conservatively 
Table I Series with conservatively and operatively treated patients

\begin{tabular}{|c|c|c|c|c|c|c|c|c|c|c|}
\hline \multirow[t]{2}{*}{ Series } & \multirow[t]{2}{*}{$n$} & \multicolumn{3}{|c|}{ Fracture level } & \multicolumn{2}{|c|}{ Frankel grade } & \multicolumn{2}{|c|}{ Neurology } & \multicolumn{2}{|c|}{ Complications } \\
\hline & & $\mathrm{T}$ & T12-L1 & $\mathrm{L}$ & $\mathrm{A}-\mathrm{C}$ & D-E & Improved & Impaired & Local & Other \\
\hline \multicolumn{11}{|l|}{ Denis et al $^{33}$} \\
\hline Conservative & 39 & \multirow{2}{*}{4} & \multirow{2}{*}{20} & \multirow{2}{*}{28} & 0 & 39 & - & 6 & 5 & - \\
\hline Harrington & 13 & & & & 0 & 13 & - & - & 2 & - \\
\hline \multicolumn{11}{|l|}{ Jacobs et al ${ }^{36}$} \\
\hline Conservative & 34 & 12 & 10 & 12 & 19 & 15 & $44 \%$ & - & - & 5 \\
\hline Harrington & 59 & 13 & 25 & 20 & 30 & 28 & $53 \%$ & - & 2 & $2^{a}$ \\
\hline \multicolumn{11}{|c|}{ McEvoy \& Bradford ${ }^{34}$} \\
\hline Conservative & 22 & \multirow{2}{*}{3} & \multirow{2}{*}{32} & \multirow{2}{*}{18} & 6 & 10 & 1 & 3 & 1 & 3 \\
\hline Operative & 31 & & & & 20 & 17 & 22 & - & 5 & 6 \\
\hline \multicolumn{11}{|l|}{ Osti et $a l^{39}$} \\
\hline Conservative & 30 & \multirow{2}{*}{ - } & \multirow{2}{*}{33} & \multirow{2}{*}{37} & 1 & 29 & 4 & - & - & 9 \\
\hline Harrington & 40 & & & & 8 & 32 & 13 & - & 17 & $16^{a}$ \\
\hline \multicolumn{11}{|l|}{ Soreff $e t a l^{37}$} \\
\hline Conservative & 20 & 10 & 9 & 1 & 10 & 10 & 12 & - & - & 9 \\
\hline Harrington & 18 & 4 & 5 & 9 & 2 & 16 & 14 & - & 1 & 2 \\
\hline \multicolumn{11}{|l|}{ Willén et $a l^{38}$} \\
\hline Conservative & 24 & 0 & 21 & 3 & 8 & 16 & 7 & - & - & 15 \\
\hline Harrington rods & 26 & 1 & 20 & 6 & 10 & 16 & 11 & - & 5 & 13 \\
\hline
\end{tabular}


treated patients were able to do so. The functional benefits of operation are thus clear, and it seems obvious that a patient with a spinal cord injury may have the same functional benefits of a similar operation. In the series of Gotzen et al ${ }^{42}$ nine out of 14 operatively stabilised patients who did not have major neurological deficits regained full working capacity, while only three of 11 conservatively treated patients did so.

Provided that the spine can be stabilised without further damage, there should be little doubt about the benefits of early mobilisation and ambulation of the patient to the extent that the neurological deficit allows. Although the psychological adaptation to the injury takes time, it seems beneficial for the patient to have a stable spine which allows early mobilisation.

\section{Conclusions}

No study can conclusively show that operative treatment improves the neurological status compared with conservative care. However, mobilisation is quicker and easier which improves the psychological and social rehabilitation. Also, such patients experience less chronic back pain. Obviously, operative treatment requires a high level of expertise; this demand is in full concert with the general need for the centralisation of the treatment of these relatively rare and severe injuries.

\section{References}

1 Lucas JT, Ducker TB (1978) Laminectomy in acute cord injury. Neurosurgery 3: 231-2.

2 Morgan TH, Wharton GW, Austin GN (1971) The results of laminectomy in patients with incomplete spinal cord injuries. Paraplegia 9: 14-23.

3 Bedbrook G (1979) Spinal injuries with tetraplegia and paraplegia. J Bone Joint Surg Br 61: 267-278.

4 Burke DC, Murray DD (1976) The management of thoracic and thoraco-lumbar injuries of the spine with neurological involvement. J Bone Joint Surg Br 58: 72-78.

5 Dickson JH, Harrington PR, Erwin WD (1978) Results of reduction and stabilization of the severely fractured thoracic and lumbar spine. J Bone Joint Surg Am 60: 799-805.

6 Guttmann L (1976) Spinal Cord Injuries-Comprehensive Management and Research. 2nd edn. Blackwell, Oxford.

7 Holdsworth F (1970) Fractures, dislocations and fracture-dislocations of the spine. J Bone Joint Surg Am 52: $1534-1551$.

8 White AA III, Panjabi M (1978) Clinical Biomechanics of the Spine. Lippincott, Philadelphia

9 Whitesides TE (1977) Traumatic kyphosis of the thoracolumbar spine. Clin Orthop 128: 78-92.

10 Denis F (1983) The three column spine and its significance in the classification of acute thoracolumbar spinal injuries. Spine 8: 817-831.

11 McAfee PC, Yuan HA, Fredrickson BE, Lubicky JP (1983) The value of computed tomography in thoracolumbar fractures. J Bone Joint Surg Am 65: 461-473.

12 Esses SI, Botsford DJ, Wright T, Bednar D. Bailey S (1991) Operative treatment of spinal fractures with the AO internal fixator. Spine 16 (Suppl): S146-150.

13 Lindsey RW, Dick W (1991) The fixateur interne in the reduction and stabilization of thoracolumbar spine fractures in patients with neurologic deficit. Spine 16 (Suppl): S140-145.

14 Watson-Jones R (1955) Fractures and dislocations of the spine with paraplegia. In Fractures and Joint Injuries. Livingstone, Edinburgh: 984-1018.

15 Flesch J, Leider L, Erickson D et al (1977) Harrington instrumentation and spine fusion for unstable fractures and fracture-dislocations of the thoracic and lumbar spine. J Bone Joint Surg Am 59: 143-153.

16 Riebel GD, Yoo JU, Fredrickson BE, Yuan HA (1993) Review of Harrington rod treatment of spinal trauma. Spine 18: 479-491.

17 Gertzbein SD, Macmichael D. Tile M (1982) Harrington instrumentation as a method of internal fixation in fractures of the spine. J Bone Joint Surg Br 64: 526-529.

18 Rimoldi RL, Zigler JE, Capen DA, Hu SS (1992) The effect of surgical intervention on rehabilitation time in patients with thoracolumbar and lumbar spinal cord injuries. Spine 17: 1443-1449.

19 Wörsdörfer O (1981) Operative Stabilisierung der thorakolumbalen und lumbalen Wirbelsäule: vergleichende biomechanische Untersuchungen zur Stabilität und Steifigkeit verschiedener dorsaler Fixationssysteme. Habilitationsschrift Klinisch Medizinische Fakultät Ulm.

20 Dick W (1984) Innere Fixation von Brust- und Lendenwirbelfrakturen. Verlag Hans Huber, Bern.

21 Convery FR, Minteer MA, Smith RW, Emerson SM (1978) Fracture-dislocation of the dorsal-lumbar spine. Acute operative stabilization by Harrington instrumentation. Spine 3: 160-166.

22 Kostuik JP (1988) Anterior fixation for burst fractures of the thoracic and lumbar spine with or without neurological involvement. Spine 13: 286-293. 
23 Bradford DS, Akbarnia BA, Winter R, Seljeskog EL (1977) Surgical stabilization of fracture and fracture-dislocation of the thoracic spine. Spine 2: 185-196.

24 Jodoin A, Dupuis P. Fraser M, Beaumont P (1985) Unstable fractures of the thoracolumbar spine: A 10-year experience at Sacre-Coeur Hospital. J Trauma 25: 197-202.

25 Capener N. (1934) Personal communication to GR Girdlestone. Cited in: Platt H, editor. Modern Trends in Orthopaedics. Paul B Hoeber Inc, New York, 1950.

26 Dall BE, Stauffer ES (1988) Neurologic injury and recovery patterns in burst fractures at the T12 or L1 motion segment. Clin Orthop 233: 171-176.

27 Gertzbein SD, Crowe PJ, Fazl M et al (1992) Canal clearance in burst fractures using the AO internal fixator. Spine 17: 558-560.

28 Herndon WA, Galloway D (1988) Neurologic return versus cross-sectional canal area in incomplete thoracolumbar spinal cord injuries. J Trauma 28: 680-683.

29 Fidler MW (1988) Remodelling of the spinal canal after burst fracture. A prospective study of two cases. J Bone Joint Surg Br 70: 730-732.

30 Kinoshita H, Nagata Y, Ueda H, Kishi K (1993) Conservative treatment of burst fractures of the thoracolumbar and lumbar spine. Paraplegia 31: 58-67.

31 Frankel HL, Hancock DO, Hyslop G et al (1969) The value of postural reduction in the initial management of closed injuries of the spine with paraplegia and tetralegia. Part I. Paraplegia 7: 179-192.

32 Alho A, Benterud J, Høgevold HE et al (1992) Comparison of functional bracing and locked intramedullary nailing in the treatment of displaced tibial shaft fractures. Clin Orthop 277: 243-250.

33 Denis F, Armstrong GWD, Searls K, Matta L (1984) Acute thoracolumbar burst fractures in the absence of neurologic deficit. A comparison between operative and nonoperative treatment. Clin Orthop 189: $142-149$.

34 McEvoy RD, Bradford DS (1985) The management of burst fractures of the thoracic and lumbar spine. Experience in 53 patients. Spine 10: 631-637.

35 Weinstein JN, Collalto P, Lehmann TR (1988) Thoracolumbar burst fractures treated conservatively: a long-term follow-up. Spine 13: 33-38.

36 Jacobs RR, Asher MA, Snider RK (1980) Thoracolumbar spinal injuries. A comparative study of recumbent and operative treatment in 100 patients. Spine 5: 463-477.

37 Soreff J, Axdorph G, Bylund P et al (1982) Treatment of patients with unstable fractures of the thoracic and lumbar spine. A follow-up study of surgical and conservative treatment. Acta Orthop Scand 53: $369-381$.

38 Willén J, Lindahl S, Nordwall A (1985) Unstable thoracolumbar fractures: A comparative clinical study of conservative treatment and Harrington instrumentation. Spine 10: 111-122.

39 Osti OL, Fraser RD, Cornish BL (1987) Fractures and fracture-dislocations of the lumbar spine. A retrospective study of 70 patients. Int Orthop 11: 323-329.

40 Strømsøe K, Alho A (1992) Die transpedikuläre Fixation nach Dick in der Behandlung vor Frakturen der Lendenwirbelsäule. Osteosynthese International (ed G Berentey). Aesculart Verlag, Budapest: 78-79.

41 Gaines RW, Humphreys WG (1984) A plea for judgment in management of thoracolumbar fractures and fracture-dislocations. Clin Orthop 189: 36-42.

42 Gotzen L, Puplat D, Junge A (1992) Indikation, Technik und Ergebnisse monosegmentaler dorsaler Spondylodesen bei Keilkompressionsfrakturen (Grad II) der thorakolumbalen Wirbelsäule. Unfallchirurg 95: $445-454$. 